\title{
RUIDO BLANCO: RUIDO PARA UNA ESCUCHA SEGURA
}

\section{Raúl León Mendoza}

Universidad Politécnica de Valencia

\section{Resumen:}

Por acción de diversos dispositivos (electrónicos, administrativos, urbanos, económicos, políticos, sociales) hemos perdido la capacidad de administrar el sonido que producimos con nuestro cuerpo y la posibilidad de clasificarlo como íntimo o público. Nuestras comunicaciones a través del sonido, que por defecto deberían ser privadas e intimas, se producen en contextos donde potencialmente pueden ser escuchadas, registradas y redistribuidas. Ruido blanco es una tentativa de recuperar la autonomía en la comunicación, de generar una estría capaz de devolvernos la seguridad de comunicarnos en igualdad, que pasa necesariamente por anular el registro sonoro. Reconstituir algunas certezas sobre la cualidad de un espacio limpio y en sombra, libre de registro, igualitario y por lo tanto un espacio de confianza mutua.

Palabras clave: SONIDO; RUIDO; ESCUCHA; COMUNICACIÓN; VIGILANCIA

\section{WHITE NOISE: NOISE FOR SAFE LISTENING}

\section{Abstract}

Due to the action of several devices -ranging from electronic, administrative to urban, economic, political and social ones-, we have lost the ability to manage the sounds our bodies produce and also the ability to label them as intimate or public. Our communications through sound, which by default should be private and intimate, occur in contexts where they can eventually be heard, recorded and even redistributed. "Ruido blanco" ("White noise") is an attempt to regain autonomy in communication, to open a fissure that helps restore self-assurance to communicate on egalitarian terms, which necessarily involves cancelling sound recording. The aim is to rebuild some certainty on the quality of a clean, shady space, where nothing is recorded and communication is egalitarian, therefore leading to mutual trust.

Keywords: SOUND; NOISE; COMMUNICATION; SURVEILLANCE

\footnotetext{
León Mendoza, Raúl. 2015. "Ruido blanco: ruido para una escucha segura". AusArt 3 (2): 188-201. D0I: 10.1387/ausart.15956
}

\section{AUSART}


"Tenías que vivir -y la costumbre acababa por convertirlo en un instinto- dando por sentado que escuchaban hasta el último sonido que hacías y que, excepto en la oscuridad, observaban todos tus movimientos."

(Orwell [1949] 2013, 11)

\section{NATURALEZA LEGAL DE NUESTRO SONIDO}

Nuestro enfoque parte de considerar el sonido (nuestro sonido) como un dato personal y por lo tanto de conservar la capacidad de administrar nuestras emisiones sonoras y calificarlas entre íntimas o públicas.

La legislación española estipula que un dato de carácter personal es también cualquier información acústica referida personas físicas identificadas o identificables ${ }^{1}$. Nos centraremos en los sonidos que emitimos (o que produce nuestro cuerpo) en entornos privados o públicos y que de forma expresa clasificamos como íntimos. Entendemos lo íntimo con el deseo (por defecto) de que estos datos no sean escuchados más que por las personas con las que compartimos el espacio físico o hacia las que direccionamos nuestra comunicación sonora.

La intimidad es un Derecho Fundamental recogido en el Artículo 18 de la Constitución Española de 1978, donde además se estipula el secreto de las comunicaciones $^{2}$ y la supeditación de los medios tecnológicos ${ }^{3}$ a la garantía de la intimidad personal. En cuanto a la relación entre los datos personales y el derecho a la intimidad, el Tribunal Constitucional expresa de esta forma que:"El derecho a la intimidad permite excluir ciertos datos de una persona del conocimiento ajeno [...] el poder de resguardar su vida privada de una publicidad no querida. El derecho a la protección de datos garantiza a los individuos un poder de disposición sobre esos datos."

Para nosotros el factor desestabilizante entre estas cuestiones viene dado por el uso de diversas tecnologías (políticas, arquitectónicas, digitales, eléctricas, etc.) que suprimen las certezas sobre las cualidades de los espacios que habitamos y los convierten en un espacio liso donde la escucha asimétrica y el registro sonoro son potencialmente posibles en todo el espacio y en todo momento. 


\section{NUESTRO SONIDO EN EL MEDIO CERRADO}

El dominio del régimen visual en la sociedad contemporánea se hace patente en los modos de la arquitectura doméstica. Los muros se interponen entre nosotros y la mirada ajena de forma efectiva y económica. Sin embargo quedan fuera de protección otras consecuencias de nuestra presencia entre las que se encuentra el sonido o nuestro rastro digital de datos. Estos otros aspectos no están en el rango de lo visible y por ello no somos tan conscientes de que nos constituyen y nos dan un perfil que puede ser traducido en datos.

La evidente desatención del sonido como una manifestación de lo íntimo en el contexto privado destapa que dentro del concepto burgués de espacio privado no se esconde nada de íntimo. El modelo de vivienda impuesto por la burguesía a partir del siglo XVII se dirime en cuestiones económicas de titularidad de las propiedades y de salud pública (Foucault [1977]1989,11-3), abandonando otros aspectos que son necesarias para el desarrollo de la personalidad y que remiten a la posibilidad de ejercer una forma autónoma de ser y estar en el mundo, para la cual es imprescindible la posibilidad de un espacio real o virtual de intimidad.

Así pues el núcleo sonoro de las ideas distópicas de Orwell está prácticamente asumido, con la diferencia de que no solo es un ente estatal ${ }^{5}$ el que el que pone una oreja en los domicilios, sino la propia comunidad en la vida cotidiana $^{6}$ la que hace invivibles las desviaciones ${ }^{7}$ de lo íntimo a causa del modelo casa.

La cualidad del sonido de traspasar los muros provoca que las emisiones cotidianas que produce o provoca nuestro cuerpo, aunque estén valoradas como pertenecientes al ámbito de la intimidad, no dispongan de ningún elemento específico de protección análogo al muro para lo visual.

Sin embargo la capacidad de oír al otro sin ser visto ni oído ${ }^{8}$ es un deseo que hunde sus raíces en los dispositivos de vigilancia disciplinarios por lo que aún tenemos que pensar en su vigencia como método de modificación de conductas ${ }^{9}$. El invento panóptico incluía también su versión pansónica en forma de tubos (Bentham [1780] 1989, 78) que permitían oír el interior de cada celda.

Hay diferencias entre los modelos de escucha que propone el sistema panóptico (asimétrico) y el provocado por nuestro modelo de domicilio (simétrico). El simétrico nos lleva a pensar en la regulación de conductas por proximi- 
dad de modelos de vida que tienen que convivir en cuestión de frecuencias, volúmenes y timbres. Nos remitimos al modelo rousseauniano que Foucault explica como el de la sociedad transparente donde "cada uno desde el lugar que ocupa, pueda ver el conjunto de la sociedad" (Foucault [1977] 1989, 15). De otro lado el modelo asimétrico, que en ese momento de la Modernidad se limitaba espacialmente a entornos cerrados en los que la mirada (en este caso la escucha) se realiza de forma unidireccional. En lo disciplinario el castigo se consiste en la pérdida temporal de la ciudadanía, y el castigo se traduce, entre otras cosas, en la pérdida de la capacidad de observar al otro en igualdad de condiciones.

Lo que ocurre en ambos escenarios (simétrico y asimétrico) es que sobrevive una economía política de la escucha donde la intimidad y la restricción de la observación no se contemplan más que como medio de ejercer el poder sobre el otro. Desaparece entonces la intimidad y con ella la autonomía entendida como capacidad de decidir cuando no queremos ser escuchados.

El problema que planteaban los dispositivos disciplinarios asociados al sonido era la dificultad de mantener la asimetría (valor fundamental de lo disciplinario) (Foucault ([1975] 2004, 234). Este problema está ampliamente resuelto desde la aparición de aparatos de sonido asociados a tecnologías eléctricas. Por una parte se han desarrollado equipos con la capacidad de registrar y amplificar sonido a distancia; por otro lado a través de operaciones de miniaturización y camuflaje estos equipos se han hecho tan pequeños que pasan

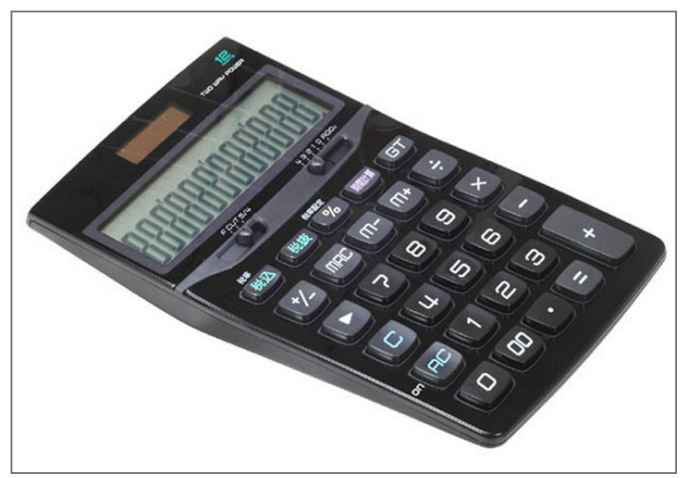

"Micrófono inalámbrico uhf oculto en calculadora" de la Factoría Espía ${ }^{10}$ desapercibidos.

Se abre entonces un espacio liso donde prevalece la potencialidad de ser escuchado y registrado en el seno de los espacios que habitualmente entendemos íntimos porque están aislados visualmente por elementos de cerramiento, muros, etc.

Así pues escuchar al otro sin que lo sepa interesa, aporta datos del otro que son una información valiosa de la que se puede disponer en nuestro bene- 


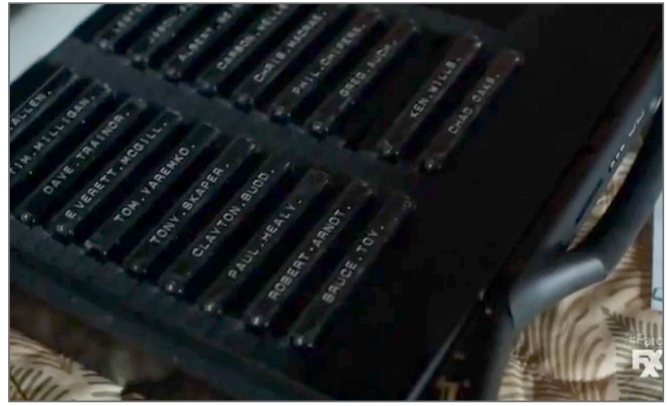

Cintas de casete de Lorne Malvo en "Fargo"11 ficio. Escuchar al otro nos proporciona en potencia una ventaja táctica. Esta potencia táctica se explota de forma comercial en sitios web que ofrecen todo tipo de productos espía, aparatos que permiten ver sin ser visto, oír sin ser escuchado, registrar sonido y video de forma oculta.

\section{NUESTRO SONIDO EN EL MEDIO ABIERTO}

La capacidad de escucha asimétrica que hemos visto en espacios considerados cerrados se extiende hacia el exterior de las instituciones de la sociedad burguesa a través de la tecnología. Con los mismos actores que en el espacio cerrado, por una parte el poder instituido en las formas del Estado y de otra a través del prójimo (comunidades de proximidad o coincidencia aleatoria).

Para la escucha entre personas en el espacio abierto se presupone la presencia de sus propios cuerpos. Este hecho nos hace suponer una simetría en el ejercicio de escucha. Pero lo que ha cambiado cualitativamente la cosa es que cualquier persona con un teléfono móvil tienen la capacidad técnica de registrar nuestros sonidos sin que seamos conscientes de ello.

Producir este tipo de registro sonoro tiene como consecuencia la conversión del sonido en objeto $^{12}$, con la posibilidad derivada de considerarlo como un bien con capacidad de disposición (reproducción, distribución, etc.) que, como hemos visto antes, nos ofrece una ventaja táctica. La extensión del uso del teléfono móvil y sus cualidades de aparato portátil con capacidades de registro audiovisual, envío de archivos a servidores remotos, junto con la popularización de las redes sociales han re-cualificado el espacio físico.

Sin ánimo de hacer juicios de valor, lo cierto es que nos aproximamos por acción de determinados usos tecnológicos hacia al contexto donde "Cada camarada se convierte en un vigilante" (Foucault [1977] 1989, 15). En palabras de Foucault el proyecto de Bentham no estaba únicamente orientado a instituciones de clausura. El sueño de Bentham era "un sistema de dispositivos 
siempre y por doquier alerta, que recorrieran las sociedad sin huecos ni interrupción" (Foucault [1975] 2004, 241).

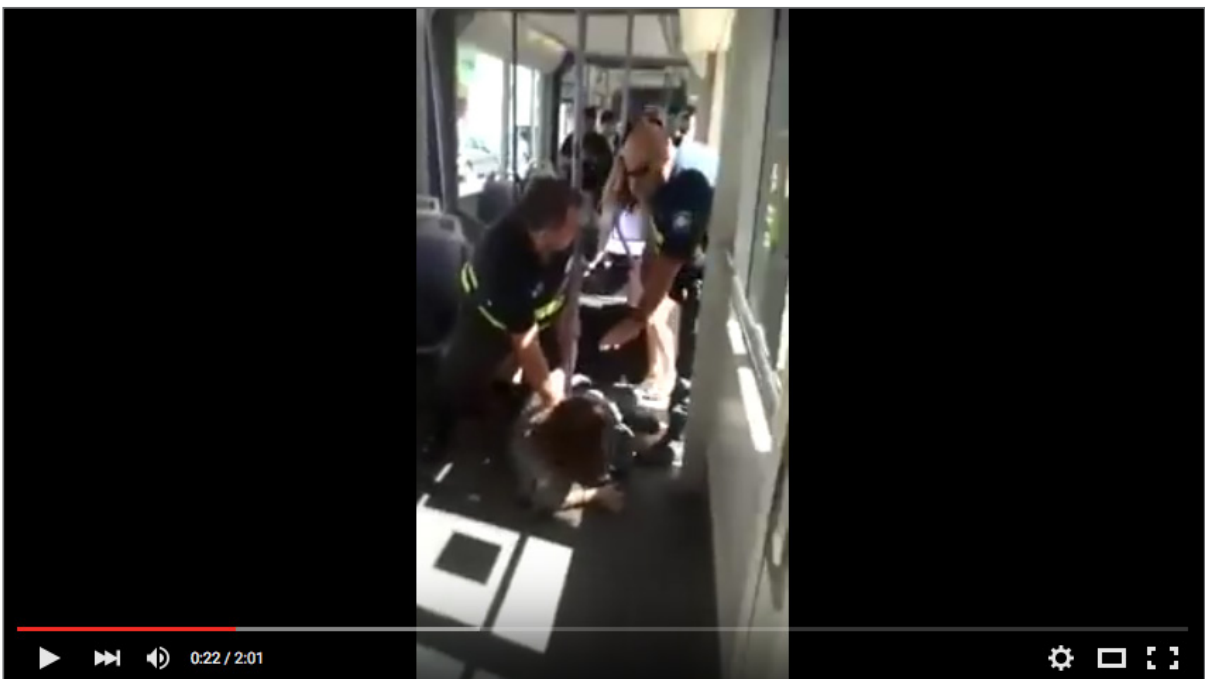

Fotograma de video "Agresión en el metro de Valencia"1 en el servidor de YouTube.

Por la parte de los regímenes Estado, constituidos como poder distribuido en diversas administraciones de la vida de los ciudadanos, los recientes acontecimientos traumáticos (11S, 11M, 15J y más cerca aún los atentados en París) marcan el desarrollo y puesta en marcha de medidas excepcionales entorno al concepto de seguridad en los espacios considerados públicos ${ }^{14}$.

Este escenario de aparente inseguridad, cuyo eje es un malentendido alrededor del concepto de seguridad ${ }^{15}$, se convierte en aparto legal por parte de las entidades Estado. En el caso español la Ley Orgánica 4/1997 por la que se regula la utilización de videocámaras por las Fuerzas y Cuerpos de Seguridad en lugares públicos, establece que "La captación, reproducción y tratamiento de imágenes y sonidos, [...], no se consideran intromisiones ilegítimas en el derecho al honor, a la intimidad personal y familiar y a la propia imagen,"16. Lo que supone de facto que para las Fuerzas y Cuerpos de Seguridad del Estado no existe en ningún caso la protección de la intimidad en temas de seguridad, puesto que este tratamiento de datos es siempre legítimo.

También se establece en esta Ley Orgánica la mecánica administrativa que prevé instalaciones de captación de forma móvil y con ello aquel espacio 


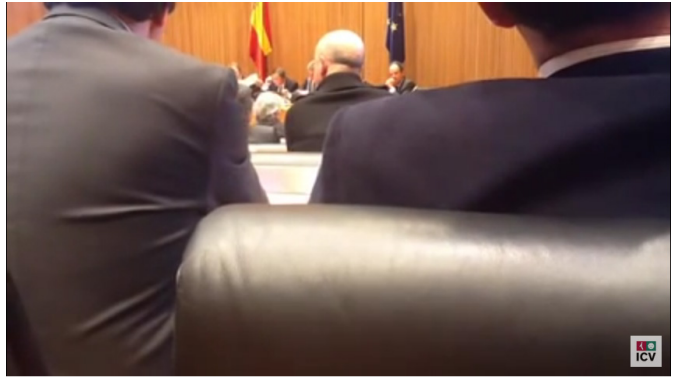

Fotograma de video "Open Draghi: ells tanquen el Congrés, nosaltres l'obrim!"'7 perteneciente la comparecencia de Mario Draghi al Congreso de los Diputados ${ }^{18}$ el 12/02/2013. estriado característico de las sociedades-con-Estado (Deleuze \& Guattari [1980] 2006a, 366), que se mantiene en la pauta de fijar cuantitativamente y cualitativamente el espacio marcado como vigilado, abre la posibilidad de surgir en cualquier punto (361), en cualquier momento. En este sentido el Estado parece jugar con nosotros una partida de ajedrez al mismo tiempo que de go (366).

Esta apropiación, por parte del poder instituido, de elementos que le son exteriores esta prevista por Deleueze y Guattari en el texto que estamos citando.

"La máquina de guerra inventa la velocidad y el secreto, sin embargo hay una determinada velocidad y un determinado secreto que pertenecen al Estado, relativamente, secundariamente."

(Deleuze \& Guattari [1980] 2006a, 362).

El mismo espacio administrado por el Estado parece alisarse en dos planos diferentes según los estratos sociales de sus actores. Continuando con la lógica de una sociedad divida en gobernantes-gobernados, que determina lo que no se puede escuchar y lo separa de lo que puede ser potencialmente escuchado en todo momento y en todos los lugares.

Estas operaciones aplanan nuestro espacio (el que es vivido por las clases no privilegiadas socialmente), lo des-estrían para desestructurarlo. Espacios considerados públicos y privados se igualan al carecen de la seguridad de comunicarse en simetría y por lo tanto nunca tenemos las condiciones que es precisa para que lo íntimo tenga lugar. Vivimos en una planitud de potencial escucha que nos impide el secreto íntimo, mientras que por otro lado se generan planos privilegiados de perpetuo secreto. Economía de la escucha del régimen acústico.

El círculo de la administración del sonido en el espacio público se cierra cuando las Fuerzas y Cuerpos de Seguridad del Estado emplean dispositivos que impiden la comunicación y agreden a la población civil a través del sonido. 


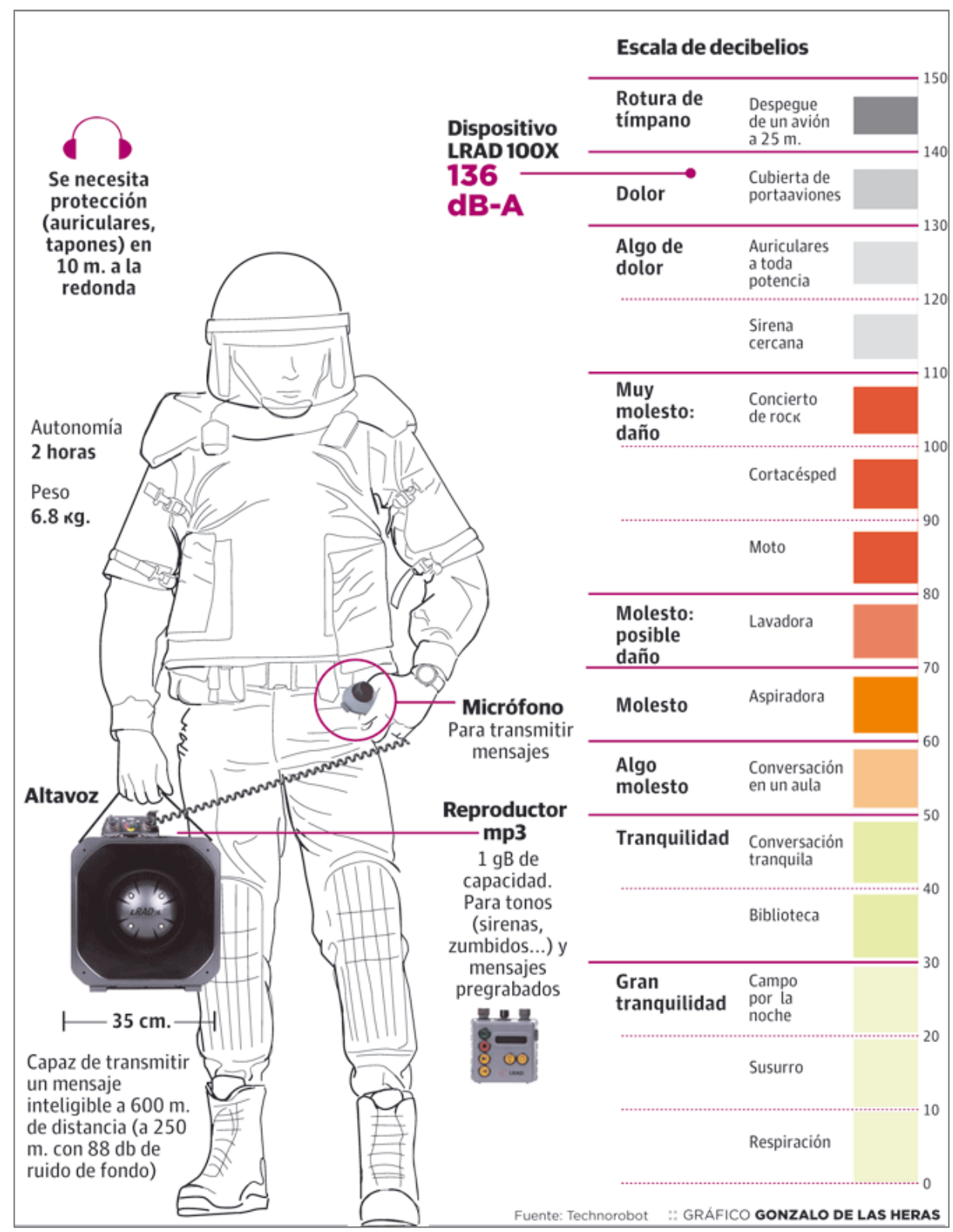

Gráfico sobre el "Cañón sónico"19 aparecido en el artículo de prensa "Decibelios por pelotas”20Diario El Correo.

Como aparato de administración de la vida, el Estado se reserva la potestad de aplicar en su seno normas que le vienen dadas por su naturaleza (leyes) 
o suprimirlas para decretar periodos o zonas de excepción (León Mendoza 2013b) colapsando el tiempo y el espacio (Weizman 2015). Es decir, aplicar la legislación o aplicar lógicas de la máquina de guerra (Deleuze \& Guattari [1980] 2006b). En este sentido Weizman en "Caminar atravesando muros" (2015) pone de manifiesto como el Estado a través de sus múltiples agentes (en este caso militares) también es capaz de ocupar su propio espacio, de distribuirse en un espacio abierto (la totalidad de su territorio) y de surgir en cualquier punto (y también en cualquier momento), en definitiva de alisar el espacio (Weizman 2015) en operaciones que conllevan moverse por el interior de las casas (de casa en casa) abriendo agujeros en los muros. Con esta operación el espacio urbano se vuelve un guante al revés, destruyendo así la clasificación que hemos establecido en este texto entre medio cerrado frente a medio abierto.

“...las operaciones militares van más allá de la destrucción física y social, lo que nos obliga a reflexionar sobre la 'destrucción conceptual' de las categorías políticas que ello implica."

\section{RUIDO BLANCO}

"El Estado no cesa de producir círculos ideales, pero se necesita una máquina de guerra para hacer un redondel."

(Deleuze \& Guattari [1980] 2006a).

Consideramos la escucha asimétrica, entendida aquí como la recepción o la grabación indeseada de un sonido que pensamos que nos pertenece, como una tecnología de vigilancia de raíz disciplinaria (pero de plena vigencia en nuestras sociedades de control) que supone la suspensión temporal de nuestro derecho fundamental a la intimidad.

“... en el espacio y durante el tiempo que ejercen su control y utilizan las disimetrías de su poder, efectúan una suspensión, jamás total, pero jamás anulada, del derecho."

(Foucault [1975] 2004, 256)

En último extremo (y en los últimos días) la cuestión urgente de la seguridad ha llevado a varios gobiernos europeos a decretar el Estado de excepción y 
por consiguiente a la suspensión directa de derechos y libertades fundamentales. Sin embargo, decisiones políticas basadas en "clausulas generales e indeterminadas" referidas a la seguridad y la salud han ido penetrando desde hace décadas en las legislaciones de los países occidentales, erosionado y haciendo ceder el territorio de las libertades y derechos personales ${ }^{21}$. "Bajo la forma jurídica general que garantizaba un sistema de derechos en principio igualitarios estaban, en forma subyacente, esos mecanismos menudos, cotidianos y físicos, todos esos sistemas de micropoder esencialmente inigualitarios y disimétricos..." (Foucault [1975] 2004, 256) han hecho posible la extensión plana y homogénea del espacio potencialmente vigilado, y por lo tanto potencialmente escuchado.

Es conocido como ruido blanco la señal sonora que contiene todas las frecuencias audibles con la misma potencia. La emisión de ruido blanco con un volumen por encima de 80 decibelios enmascara cualquier voz o sonido emitido por el cuerpo.

Partiendo de la conciencia de en que nuestro medio cotidiano estamos continuamente expuestos a ser escuchados o registrados, nos planteamos como forma de antagonismo constituir un espacio inaudible que imposibilitara el registro como contraposición al espacio continuo de escucha potencial.

Pensando en todo lo que no está protegido como potencialmente explotable por terceros, planteamos un entorno donde el pacto sea la escucha con garantías de intimidad, con la certidumbre de que el sonido emitido no es almacenable más que en la memoria de los participantes.

Entendiendo todo lo que se puede escuchar como aquello que es visible y a la propia visibilidad como "una trampa" (Foucault [1975] 2004, 232), "RuidoBlanco" es una especie de TAZ (Hakim 2014) que dispone una ruptura (una estría) que a modo de muro sonoro invierte la economía de lo audible propiciando un lugar temporalmente autónomo en el espacio continuo potencialmente vigilado.

Para nosotros no se trata de conjurar fantasmas conspiranoicos que presuponen una escucha constante (una mirada continua) sobre nuestras vidas por parte de una exterioridad que todo lo sabe. El ruido blanco nos sirve para re-colocar un muro (más o menos simbólico, pero efectivo) que recupere para nosotros lo que es nuestro (nuestro sonido) y nos vuelva a poner en posi- 
ciones donde lo privado pueda ser también íntimo como condición esencial de ser en el mundo.

Un muro sonoro capaz de reconstituir nuestra confianza en el espacio y entre nosotros, tal y como Wiezman (2015) habla del muro físico entorno a su posible desvanecimiento.

"El combate urbano contemporáneo, se ocupa crecientemente de los métodos para transgredir el tipo de limitaciones que se materializan en el muro doméstico. A este respecto, podría resultar útil pensar sobre los muros (domésticos) de la ciudad como se piensa en la muralla de la ciudad (cívica): como bordes que hacen operativa la ley y como condición de la vida urbana democrática."

"RuidoBlanco" es una instalación sonora que emplea el ruido como obstáculo para evitar la escucha y el registro del sonido por parte de agentes externos a los propios usuarios. Cada usuario dispone de un micrófono y unos auriculares y puede comunicarse simultáneamente con los otros tres usuarios. Alrededor de los usuarios se establece una zona de ruido donde la comunicación, la escucha o el registro son inviables.

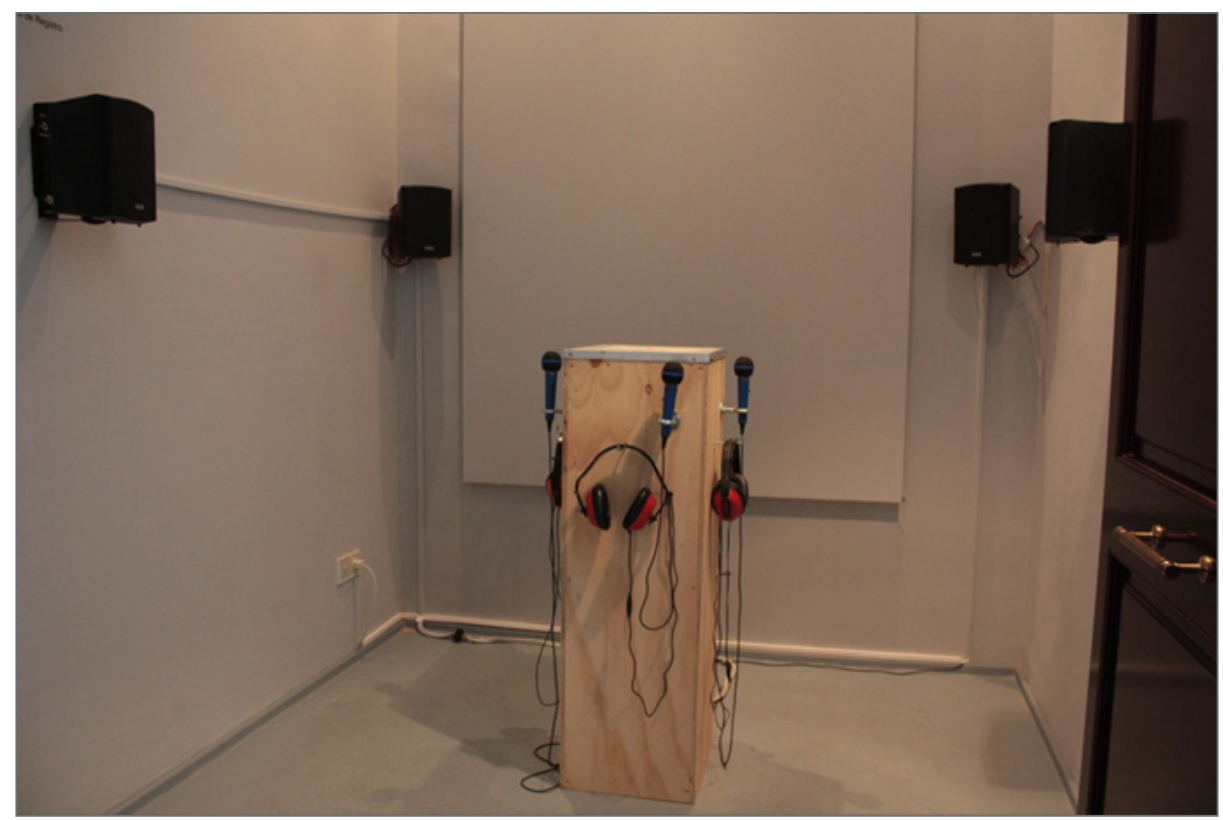

Imagen de la instalación "RuidoBlanco" en la muestra "Art you can eat"22(Valencia, 2013). 


\section{Referencias}

Apaolaza Fernández, Francisco. 2014. "Decibelios por pelotas". El Correo, 1 feb. http:// www.elcorreo.com/vizcaya/20140201/mas-actualidad/sociedad/decibelios-pelotas-201401291830.html

Bentham, Jeremy (1780) 1989. El Panóptico; El ojo del poder [de] Michel Foucault; Bentham en España [de] María Jesús Miranda

De las Heras Palmero, Gonzalo. 2014. "Ruido contra las masas: Así es el cañón sónico que usan los antidisturbios". Gráfico ilustrativo en "Decibelios por pelotas", por Francisco Apaolaza. El Correo, 1 feb. http://info.elcorreo.com/graficos/2014/canon-sonico/

Deleuze, Gilles \& Félix Guattari. (1980) 2006a. Mil mesetas: capitalismo y esquizofrenia. Traducción de José Vázquez Pérez. Valencia: PreTextos

- (1980) 2006b. "Tratado de nomadología: La máquina de guerra." En Mil mesetas: capitalismo y esquizofrenia. Valencia: PreTextos

Foucault, Michel. (1975) 2004. Vigilar y Castigar: Nacimiento de la Prisión. Traducción de Aurelio Garzón del Camino. Madrid: Siglo XXI

- (1977) 1989. El ojo del poder. [Entrevista por Jean-Pierre Barou y Michelle Perrot]. Madrid: La Piqueta

Gómez Rodríguez, Carlos. 2015. "Agresión en el metro de Valencia”. Vídeo de Youtube, 02:01. 28 de mayo https://www.youtube.com/watch?v=I2MzGOh iLc

Hakim, Bey. 2014. T.A.Z.: Zona temporalmente autónoma. Madrid: Enclave de Libros

Hawley, Noah. 2014. "La encrucijada de Morton" [Morton's Fork]. Fargo, Temp. 1, Episodio 10. Dirigido por Matt Shakman

Iniciativa per Catalunya Verds. 2013. "Open Draghi: ells tanquen el Congrés, nosaltres l'obrim!". Vídeo de Youtube, 01:37. 12 de feb. https://www.youtube.com/watch?time continue=11\&$\mathrm{v}=\mathrm{slcCbMKmsoc}$

León Mendoza, Raúl. 2013a. "Acceso: Del obstáculo al ejercicio de Acceso". Trabajo fin de máster Univ. Politécnica Valencia. https://riunet.upv.es/bitstream/handle/10251/37910/ Leon_Mendoza_Raul_ACCESO.pdf?sequence $=1$ \&isAllowed $=y$

_ 2013b. "Rights saying, goodbye". En "Acceso: Del obstáculo al ejercicio de Acceso", trabajo fin de máster Univ. Politécnica Valencia http://www.486.es/docs/Leon Mendoza Raul ACCESO_.pdf

Miguel Ahumada et al. 2013. Art you can eat. Catálogo de la exposición. Valencia: Caja Mediterráneo

Orwell, George. (1949) 2013. 1984. Traducción de Miguel Temprano García. Madrid: Random House Mondadori

Segovia, Carlos y Luis Ángel Sanz. 2013. "Draghi publica su discurso tras el bloqueo del Congreso a su retransmisión". El Mundo, 12 feb. http://www.elmundo.es/elmundo/2013/02/12/ economia/1360674464.html

Weizman, Eyal. 2015. "Caminar atravesando muros". Traducción de Marcelo Expósito, revisada por Joaquín Barriendos. eipcp.net [Instituto Europeo para Políticas Culturales Progresivas]. Acceso 28 nov. http://eipcp.net/transversal/0507/weizman/es 


\section{Normas jurídicas}

Constitución Española, 1978

Ley Orgánica 4/1997 de 4 de agosto, por el que se regula la utilización de videocámaras por las Fueras y Cuerpos de Seguridad en lugares públicos (BOE núm. 186, de 5 de ago. 1997)

Real Decreto 1720/2007 por el que se aprueba el reglamento de desarrollo de la Ley Orgánica 15/1999, de 13 de diciembre de protección de datos de carácter personal (BOE núm. 17, de 19 ene 2008)

Tribunal Constitucional (Pleno). Sentencia núm. 292/2000 de 30 de Noviembre, fj 6 (BOE núm. 4 , de 4 ene 2001)

Notas

${ }^{1}$ Artículo 5.1.f. del Real Decreto 1720/2007 por el que se aprueba el reglamento de desarrollo de la Ley Orgánica 15/1999, de 13 de diciembre de protección de datos de carácter personal.

${ }^{2}$ Art. 18.3 Constitución Española

${ }^{3}$ Art. 18.4 Constitución Española

${ }^{4}$ Sentencia núm. 292/2000 del Pleno del Tribunal Constitucional (30 nov.), Fundamento Jurídico 6

${ }^{5}$ Aunque nos hemos centrado solo en la cuestión de la proximidad, tenemos que mencionar algunos aspectos destacados en torno a injerencias en el espacio privado por parte de terceros, como son los escándalos destapados en relación entorno a la injerencia en comunicaciones privadas de diferentes agencias de inteligencia; cesiones legislativas en la protección de los derechos fundamentales a la intimidad y al secreto relacionados con la figura del sospechoso.

${ }^{6}$ Por poner un ejemplo, acostado en mi cama se cuando mi vecino de arriba está orinando aunque no lo vea.

${ }^{7}$ En este sentido cualquier salida de tono es autorregulada en una comunidad de convivencia próxima como una comunidad de vecinos. Solo son permitidas algunas desviaciones de lo general que tienen que ver con el trabajo, pero cualquier otro momento o aspecto que se salga de las pautas generales está restringido y prácticamente anulado.

${ }^{8}$ En adelante a esto lo denominaremos como asimetría.

${ }^{9}$ Foucault insiste sobre el tema de la relación entre el modelo de visibilidad panóptico y sus efectos de modificación automática de conducta: "El que está sometido a un campo de visibilidad, y que sabe que lo está, reproduce por su cuenta las coacciones del poder; las pone en juego espontáneamente sobre sí mismo; inscribe en sí la relación de poder en la cual juega simultáneamente los dos papeles; se convierte en el principio de su propio sometimiento" ([1975] 2004, 235).

10 "Micrófono inalámbrico uhf oculto en calculadora : Código Producto 285". En catálogo web de Factoria Espia. Acceso 28 nov. 2015. http://www.factoriaespia.com/microfonos/microfonos espia/microfono inalambrico uhf oculto en calculadora.html 
11 Hawley, Noah. 2014. "La encrucijada de Morton" [Morton's Fork]. Fargo, Episodio 10 de la Temporada 1. Dirigido por Matt Shakman.

${ }^{12}$ Cuando nos referimos a un objeto no solo pensamos en algo físico como una cinta de casete, extendemos este término desde los cilindros de Edison, hasta los archivos digitales de audio guardados en cualquier soporte.

${ }^{13}$ Vídeo de Youtube "Agresión en el metro de Valencia", Carlos Gómez Rodríguez. 28 de mayo de 2015 (2'01) https://www.youtube.com/watch?v=I2MzGOh iLc.

${ }^{14}$ Aunque nos gustaría no podemos entrar en detalle sobre todas las restricciones a las libertades impuestas por la actual coyuntura del miedo, entre las que se encuentran, la capacidad de extensión del rol de sospechoso a la totalidad del cuerpo social y por lo tanto la posibilidad de extraerle datos en formato sonoro con ciertas restricciones en las garantías de otros derechos.

${ }^{15} \mathrm{Al}$ menos desde nuestro punto de vista, el sentido que la Constitución Española de 1978 da al derecho fundamental a la seguridad no tiene nada que ver al significado que ha adquirido socialmente de autoprotección, rechazo y prevención. Véase Artículo 17.1 CE.

${ }^{16}$ Artículo 2.1 de la Ley Orgánica 4/1997 de 4 de agosto, por el que se regula la utilización de videocámaras por las Fueras y Cuerpos de Seguridad en lugares públicos.

${ }^{17}$ Vídeo de Youtube "Open Draghi: ells tanquen el Congrés, nosaltres l'obrim!", Iniciativa per Catalunya Verds. 12 de feb. 2013 (1'37) https://www.youtube.com/watch?time continue $=11 \& \mathrm{v}=$ slcCbMKmsoc

${ }^{18}$ Jesús Posada (Presidente del Congreso de los Diputados) intento restringir por medios técnicos el registro sonoro y visual de esta comparecencia. Véase "Draghi publica su discurso tras el bloqueo del Congreso a su retransmisión", de Carlos Segovia y Luis Ángel Sanz. El Mundo, 12 feb. 2013. http://www.elmundo.es/elmundo/2013/02/12/economia/1360674464. html.

${ }^{19}$ Gráfico ilustrativo "Ruido contra las masas: Así es el cañón sónico que usan los antidisturbios" por Gonzalo De las Heras en "Decibelios por pelotas", por Francisco Apaolaza. El Correo, 1 feb. de 2014. http://info.elcorreo.com/graficos/2014/canon-sonico/.

20 "Decibelios por pelotas", por Francisco Apaolaza. El Correo, 1 feb. de 2014. http://www.elcorreo.com/vizcaya/20140201/mas-actualidad/sociedad/decibelios-pelotas-201401291830. $\underline{\mathrm{html}}$.

${ }^{21}$ Hemos reflexionado sobre la seguridad y la intimidad entorno a la expansión de la videovigilancia (León Mendoza 2013a)

${ }^{22}$ Art you can eat (2013), catálogo de la exposición. Miguel Ahumada et al. Valencia: Caja Mediterráneo 